\title{
Steroidogenic factor-1 hypermethylation in maternal rat blood could serve as a biomarker for intrauterine growth retardation
}

\author{
Dong-Mei $\mathrm{Wu}^{1,{ }^{1},}$, Liang-Peng $\mathrm{Ma}^{1,3,{ }^{*}}$, Gui-Li Song ${ }^{2}$, Yong Long ${ }^{2}$, Han-Xiao Liu ${ }^{1}$, Yang \\ Liu ${ }^{1}$ and Jie Ping ${ }^{1}$ \\ ${ }^{1}$ Department of Pharmacology, Wuhan University School of Basic Medical Sciences, Wuhan 430071, China \\ ${ }^{2}$ Key Laboratory of Biodiversity and Conservation of Aquatic Organism, Institute of Hydrobiology, Chinese Academy of \\ Sciences, Wuhan 430072, China \\ ${ }^{3}$ Department of Pharmacy, Wuhan First Hospital, Wuhan 430022, Hubei, China \\ *These authors have contributed equally to this work \\ Correspondence to: Jie Ping, email: pingjie@whu.edu.cn \\ Keywords: steroidogenic factor-1 (SF-1); DNA methylation; intrauterine growth retardation (IUGR); clustered regularly interspaced \\ short palindromic repeats/CRISPR-associated protein 9 (CRISPR/Cas9); biomarker \\ Received: July 11,2017 Accepted: September 21, 2017 Published: October 10, 2017 \\ Copyright: Wu et al. This is an open-access article distributed under the terms of the Creative Commons Attribution License 3.0 \\ (CC BY 3.0), which permits unrestricted use, distribution, and reproduction in any medium, provided the original author and source \\ are credited.
}

\section{ABSTRACT}

Intrauterine growth retardation (IUGR) is a common obstetric complication lacking an optimal method for prenatal screening. DNA methylation profile in maternal blood holds significant promise for prenatal screening. Here, we aimed to screen out potential IUGR biomarkers in maternal blood from the perspective of DNA methylation. The IUGR rat model was established by prenatal maternal undernutrition. Highthroughput bisulfite sequencing of genomic DNA methylation followed by functional clustering analysis for differentially methylated region (DMR)-associated genes demonstrated that genes regulating transcription had the most significantly changed DNA methylation status in maternal blood with IUGR. Genes about apoptosis and placental development were also changed. Besides increased placental apoptosis, IUGR rats demonstrated the same hypermethylated CpG sites of steroidogenic factor-1 (SF-1, a DMR-associated transcription factor about placenta) promoter in maternal blood and placentae. Further, ff1b, the SF-1 ortholog, was knocked out in zebrafish by CRISPR/Cas9 technology. The knock-out zebrafish demonstrated developmental inhibition and increased IUGR rates, which confirmed the role of SF-1 in IUGR development. Finally, hypermethylated SF-1 was observed in human maternal blood of IUGR. This study firstly presented distinct DNA methylation profile in maternal blood of IUGR and showed hypermethylated SF-1 could be a potential IUGR biomarker in maternal rat blood.

\section{INTRODUCTION}

Intrauterine growth retardation (IUGR), which refers to the poor fetal growth in uterus, is a common obstetric complication [1]. IUGR not only induces perinatal morbidity and mortality, but also increases the susceptibility to some age-related diseases in the offspring, such as hypertension and type II diabetes [2-4]. Owing to the lack of effective intrauterine treatments, the current goal of IUGR management is early detection and timely delivery $[5,6]$. Multiple methods have been combined for IUGR prediction, including biophysical profile, routine ultrasound, and molecular biological technique [7]. But there still lacks a definitively optimal method for screening IUGR during gestation.

The etiology of IUGR is largely attributed to adverse intrauterine environment during pregnancy. Epigenetics explains the relationship between gene expression and environmental signals. As a major mechanism of epigenetic modification, DNA methylation can affect the stable 
maintenance of gene expression patterns [8, 9]. Meanwhile, DNA methylation is more sensitive to environmental stimuli than DNA sequences and more stable than RNA in maternal blood [8, 10]. Maternal blood provides gas and nutrients for the developing fetus and could provide an avenue of signal exchange [7]. DNA methylation analysis in maternal blood has been considered as a non-invasive method with advantages of good accuracy and sensitivity. It has been reported that DNA methylation patterns in maternal blood could be used for non-invasive prenatal diagnosis of trisomy 21 and congenital heart defects [11, 12]. As to prenatal IUGR screening, hypermethylated RASSF1A in maternal blood was reported to be a possible IUGR biomarker [13]. It remains unclear whether genomic DNA methylation profile was generally changed in maternal blood of IUGR. And more evidence is needed to verify the role of aberrant DNA dysfunction in IUGR.

The placenta serves as an essential barrier for fetal development. Placental dysfunction-induced adverse intrauterine environment is taken as one of the predominant causes of IUGR $[6,14,15]$. And the underlying mechanism may be associated with the aberrant epigenetic modification in the placenta $[16$, 17]. steroidogenic factor-1 (SF-1) is an IUGR-related transcription factor crucial for placental development and syncytiotrophoblast apoptosis, of which the expression is associated with its promoter methylation status [1821]. As apoptotic syncytiotrophoblast cells flow into the maternal blood, placental DNA can be determined in the maternal blood $[22,23]$. Thus, the aberrant DNA methylation of genes in IUGR placenta (such as SF-1) and the subsequent placental dysfunction may be reflected by the DNA methylation patterns in maternal blood.

In this study, we aimed to demonstrate DNA methylation profile in maternal blood of IUGR and to screen out potential IUGR biomarkers. The IUGR rat model was established by maternal undernutrition during pregnancy. And we used high-throughput sequencing of genomic DNA methylation to screen out changed DNA status of genes related to fetal and placental development in maternal blood. The screen-out gene was knocked out in zebrafish to verify its role in inducing IUGR. Further, the DNA methylation pattern of the screen-out gene was confirmed in peripheral blood of clinical pregnant women with IUGR. This study will provide evidence for understanding IUGR pathophysiology and the noninvasive prenatal prediction of IUGR.

\section{RESULTS}

\section{Developmental parameters in rats}

In this study, an IUGR rat model was established successfully through prenatal maternal undernutrition. As shown in Figure 1A, maternal body weights of the control gained gradually during gestation. However, maternal body weights in the undernutrition group decreased during gestation and were significantly lower than that of the control since gestational day (GD) 3. On GD14, fetal body weights and placental weights in the undernutrition group were reduced to $75.0 \%$ and $68.8 \%$, respectively, of the control $(P<0.01$, Figure 1B). And the ratio of placental weight to fetal weight in the undernutrition group was significantly lower than that in the control $(P<0.01$, Figure $1 C)$. IUGR rate in the undernutrition group increased to $82.5 \%$, which was 44 times higher than that in the control $(P<0.01$, Figure $1 \mathrm{C})$.

\section{Genomic DNA methylation sequencing in maternal rat blood}

High-throughput genomic DNA methylation sequencing was employed to demonstrate DNA methylation profile in maternal rat blood. The majority of differentially methylated regions (DMRs) were distributed within intergenic regions, including promoters. The functional clustering analysis for top 3000 DMR-associated genes demonstrated that the most significantly changed DNA methylation patterns were in genes regulating transcription (Table 1). Placenta-related transcription factors of this cluster were shown in Table 2. Among the functional clusters related to fetal and placental development,
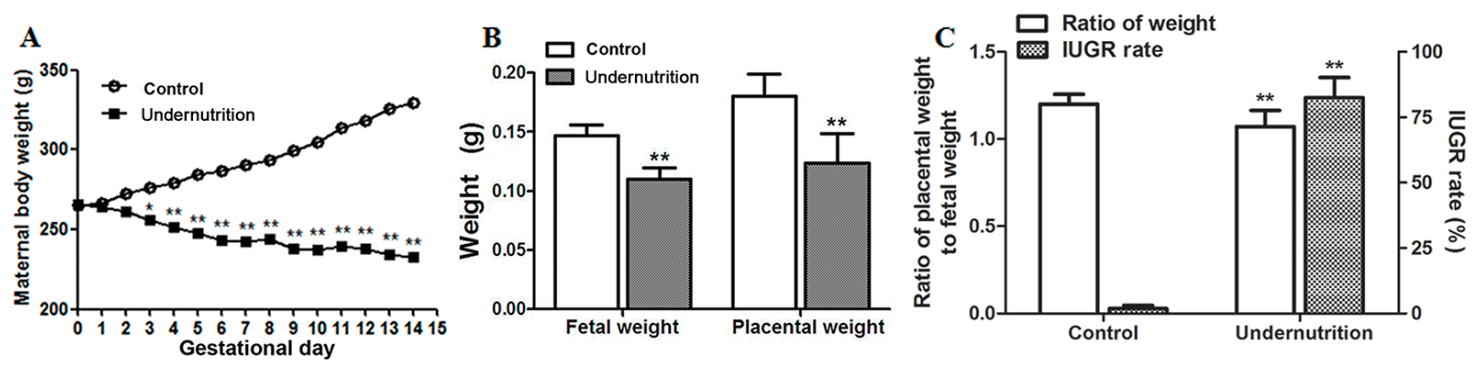

Figure 1: Developmental parameters of rats under prenatal maternal undernutrition. The pregnant rats were fed a restricted diet (50\% of the daily food intake of the control rats) from gestational day (GD) 0 to GD14. On GD14, the rats were anesthetized with isoflurane and sacrificed. (A) Maternal body weights; (B) fetal weights and placental weights; (C) intrauterine growth retardation (IUGR) rates and the ratio of placental weight to fetal weight and. Mean $\pm \mathrm{SD},{ }^{*} P<0.05,{ }^{* *} P<0.01$, two-sided $t$-test, $n=6$ control vs. 5 undernutrition pregnant rats. 
Table 1: Functional clusters for DMR associated genes

\begin{tabular}{|c|c|c|c|}
\hline GO term & Count & $P$ value & FDR \\
\hline Transcription regulation & \multicolumn{3}{|c|}{ Enrichment score: 3.46} \\
\hline GO:0030528 transcription regulator activity & 174 & 0.001 & 2.04 \\
\hline GO:0003677 DNA binding & 238 & 0.009 & 13.46 \\
\hline GO:0006350 transcription & 234 & 0.020 & 30.88 \\
\hline GO:0003700 transcription factor activity & 108 & 0.030 & 38.42 \\
\hline GO:0045449 regulation of transcription & 285 & 0.039 & 52.03 \\
\hline Apoptosis & \multicolumn{3}{|c|}{ Enrichment Score: 2.30} \\
\hline GO:0008219 cell death & 80 & 0.004 & 7.12 \\
\hline GO:0016265 death & 81 & 0.005 & 8.88 \\
\hline GO:0006915 apoptosis & 73 & 0.007 & 11.79 \\
\hline GO:0012501 programmed cell death & 73 & 0.010 & 17.05 \\
\hline Cardiac development & \multicolumn{3}{|c|}{ Enrichment Score: 1.48} \\
\hline GO:0060415 muscle tissue morphogenesis & 8 & 0.003 & 5.11 \\
\hline $\begin{array}{l}\text { GO:0055008 cardiac muscle tissue } \\
\text { morphogenesis }\end{array}$ & 8 & 0.003 & 5.11 \\
\hline GO:0003007 heart morphogenesis & 18 & 0.004 & 7.59 \\
\hline $\begin{array}{l}\text { GO:0055010 ventricular cardiac muscle } \\
\text { morphogenesis }\end{array}$ & 7 & 0.005 & 8.58 \\
\hline $\begin{array}{l}\text { GO:0048738 cardiac muscle tissue } \\
\text { development }\end{array}$ & 14 & 0.012 & 20.53 \\
\hline Neurodevelopment & \multicolumn{3}{|c|}{ Enrichment Score: 1.40} \\
\hline GO:0030030 cell projection organization & 53 & 0.007 & 12.78 \\
\hline $\begin{array}{l}\text { GO:0000904 cell morphogenesis involved in } \\
\text { differentiation }\end{array}$ & 37 & 0.013 & 20.93 \\
\hline $\begin{array}{l}\text { GO:0032989 cellular component } \\
\text { morphogenesis }\end{array}$ & 54 & 0.028 & 40.93 \\
\hline GO:0048666 neuron development & 46 & 0.030 & 42.73 \\
\hline $\begin{array}{l}\text { GO:0048667 cell morphogenesis involved in } \\
\text { neuron differentiation }\end{array}$ & 31 & 0.031 & 43.92 \\
\hline GO:0030182 neuron differentiation & 60 & 0.031 & 44.41 \\
\hline GO:0048812 neuron projection morphogenesis & 30 & 0.034 & 46.66 \\
\hline GO:0007409 axonogenesis & 28 & 0.037 & 50.05 \\
\hline Placental development & \multicolumn{3}{|c|}{ Enrichment Score: 0.86} \\
\hline $\begin{array}{l}\text { GO:0060716 labyrinthine layer blood vessel } \\
\text { development }\end{array}$ & 5 & 0.031 & 74.02 \\
\hline GO:0001890 placenta development & 15 & 0.041 & 92.43 \\
\hline
\end{tabular}

DMR, differentially methylated region; FDR, false discovery rate.

remarkable changes were observed in apoptosis, cardiac development, neurodevelopment and placental development
(Table 1). The specific genes involved in these functional clusters were shown in Table 2. 
Table 2: Genes involved in functional clusters for DMR associated genes

\begin{tabular}{|c|c|c|c|c|}
\hline Gene symbol & DMR_ID & Description & Methylation status & Fold change \\
\hline \multicolumn{5}{|c|}{ Genes about transcription regulation } \\
\hline $\mathrm{Cdx} 2$ & Chr12_dmr_912 & $\begin{array}{c}\text { caudal type homeo } \\
\text { box } 2\end{array}$ & hypermethylated & 2.99 \\
\hline Cry2 & Chr3_dmr_9973 & $\begin{array}{l}\text { cryptochrome } \\
\text { circadian clock } 2\end{array}$ & hypermethylated & 2.67 \\
\hline Rara & Chr10_dmr_13437 & $\begin{array}{l}\text { retinoic acid receptor } \\
\text { alpha }\end{array}$ & hypermethylated & 3.12 \\
\hline SF-1 & Chr3_dmr_2513 & steroidogenic factor-1 & hypermethylated & 3.67 \\
\hline \multicolumn{5}{|c|}{ Genes about apoptosis } \\
\hline Steap3 & Chr13_dmr_2602 & $\begin{array}{l}\text { STEAP family } \\
\text { member } 3, \\
\text { metalloreductase }\end{array}$ & hypomethylated & -2.01 \\
\hline Nfkb1 & Chr2_dmr_26888 & $\begin{array}{l}\text { nuclear factor of kappa } \\
\text { light polypeptide gene } \\
\text { enhancer in B-cells } 1\end{array}$ & hypomethylated & -2.56 \\
\hline Inha & Chr9_dmr_10674 & inhibin alpha & hypomethylated & -3.09 \\
\hline \multicolumn{5}{|c|}{ Genes about cardiac development } \\
\hline Tbx 1 & Chr11_dmr_11267 & T-box 1 & hypermethylated & 3.21 \\
\hline Foxc2 & Chr19_dmr_7361 & forkhead box C2 & hypermethylated & 2.42 \\
\hline Pitx2 & Chr2_dmr_26037 & $\begin{array}{c}\text { paired-like } \\
\text { homeodomain } 2\end{array}$ & hypermethylated & 2.54 \\
\hline \multicolumn{5}{|c|}{ Genes about neurodevelopment } \\
\hline Cdk5 & Chr4_dmr_868 & $\begin{array}{l}\text { cyclin-dependent } \\
\text { kinase } 5\end{array}$ & hypomethylated & 3.42 \\
\hline Lhx4 & Chr13_dmr_7436 & LIM homeobox 4 & hypermethylated & 2.89 \\
\hline \multicolumn{5}{|c|}{ Genes about placental development } \\
\hline Ncoa6 & Chr3_dmr_19379 & $\begin{array}{c}\text { nuclear receptor } \\
\text { coactivator } 6\end{array}$ & hypermethylated & 2.78 \\
\hline Ovol2 & Chr3_dmr_17597 & ovo-like zinc finger 2 & hypermethylated & 3.21 \\
\hline
\end{tabular}

DMR, differentially methylated region.

\section{DNA methylation status of SF-1 promoter in maternal rat blood}

Among the 4 differentially methylated transcription factor, SF-1 has been proven as an IUGR-related gene in our previous studies [20]. Meanwhile, SF-1 plays an important role in placental development and syncytiotrophoblast apoptosis, another two changed functional clusters $[18,19,21]$. Thus, hypermethylated SF-1 was selected for further investigation. It is widely accepted that hypermethylated gene promoter could induce inhibited gene expression via disturbing the binding with transcription factors $[10,24]$. Thus, the methylation status of $\mathrm{CpG}$ sites in the $-280 /+60$ domain of rat SF-1, which covers the binding sites for transcription factors, was verified in maternal blood. Figure 2A demonstrated the methylation map of $\mathrm{CpG}$ sites. As shown in Figure $2 \mathrm{~B}$, the total methylation rate in the undernutrition group was significantly higher than that in the control $(P<0.05)$. Among the $36 \mathrm{CpG}$ sites, nt $-235,-162,-14,-10$ and -7 showed increased frequency of single $\mathrm{CpG}$ methylation after undernutrition treatment $(P<0.05$, Figure $2 \mathrm{C})$.

\section{Placental histology and apoptosis in rats}

Increased placental apoptosis was reported to induce aberrant placental development and IUGR [25, 26]. Thus, we analyzed the histology and cell apoptosis in rat 
placentae. As compared to the control (Figure 3A), fewer syncytiotrophoblasts and more dilated intercellular spaces were shown in the IUGR placentae stained with hematoxylin and eosin (HE) (Figure 3B). In addition, TdT-mediated dUTP nick end labelling (TUNEL) staining showed increased apoptosis in syncytiotrophoblasts of IUGR placentae (Figure 3D) than that of the control (Figure 3C). The data from the semi-quantitative assay also demonstrated a statistically significant difference between the two groups $(P<0.01$, Figure $3 \mathrm{G}$ ). The same phenomenon was also observed by transmission electron microscope (TEM) analysis, which exhibited typical apoptotic morphological changes in placental syncytiotrophoblasts of the IUGR group (Figure $3 \mathrm{~F}$ ) but not in the control (Figure 3E). Specifically, these shrunken syncytiotrophoblast cells had intense chromatin structure at the periphery of nucleus (white arrows) and had cytoplasm rich in vacuoles (black arrows).

\section{mRNA expression and DNA methylation of SF-1 in rat placentae}

To explore whether the changed DNA methylation of SF-1 also occurred in placentae, we determined the DNA methylation and mRNA expression of SF-1 in rat placentae. The reverse-transcription PCR (RTPCR) analysis exhibited that SF-1 mRNA expression in the undernutrition placentae markedly reduced to $65.5 \%$ of the control $(P<0.05$, Figure $4 \mathrm{~A})$. Figure $4 \mathrm{~B}$ demonstrated the methylation map of $\mathrm{CpG}$ sites in the $-280 /+60$ domain of rat SF-1. The total methylation rate of SF-1 promoter in the undernutrition group was significantly higher than that in the control $(P<0.05$,
Figure 4C). More importantly, the hypermethylated SF-1 $\mathrm{CpG}$ sites in rat placentae were the same as those in maternal blood under prenatal maternal undernutrition $(P<0.05$, Figure 4D).

\section{Developmental parameters and mRNA expression of developmental genes in fushi tarazu factor 1b (ff1b) knockout zebrafish}

The SF-1 ortholog fflb, was knocked out in zebrafish by clustered regularly interspaced short palindromic repeats/CRISPR-associated protein 9 (CRISPR/Cas9) technology (Supplementary Figure 2). Developmental parameters of $\mathrm{F}_{3}$ zebrafish were measured to analyze the effects of fflb on zebrafish development. There were significantly decreased body lengths $(P<0.05$, Figure 5A) and increased IUGR rates $(P<0.05$, Figure 5B) in mutant-type (MT) embryos at 6 days postfertilization (dpf) in comparison to the wild-type (WT) embryos. Different from the WT group (Figure 5C, 5E), the 6-dpf MT embryos demonstrated delayed yolk sac absorption, accompanying with yolk sac edema and smaller fish bladders (Figure 5D, 5F). The body segment numbers (Figure 5G) and general morphology score (GMS) (Figure 5H) showed no significant changes at the observed time points. To evaluate the delayed embryonic development at the organogenic level, the expression of goosecoid (gsc) and krx-20 were determined in $\mathrm{F}_{3}$ zebrafish embryos at 12 hour post-fertilization (hpf). Both mRNA levels of gsc $(P<0.05$, Figure 5I) and krx$20\left(P<0.05\right.$, Figure 5J) significantly decreased in $\mathrm{F}_{3} \mathrm{MT}$ zebrafish embryos compared to the WT group.
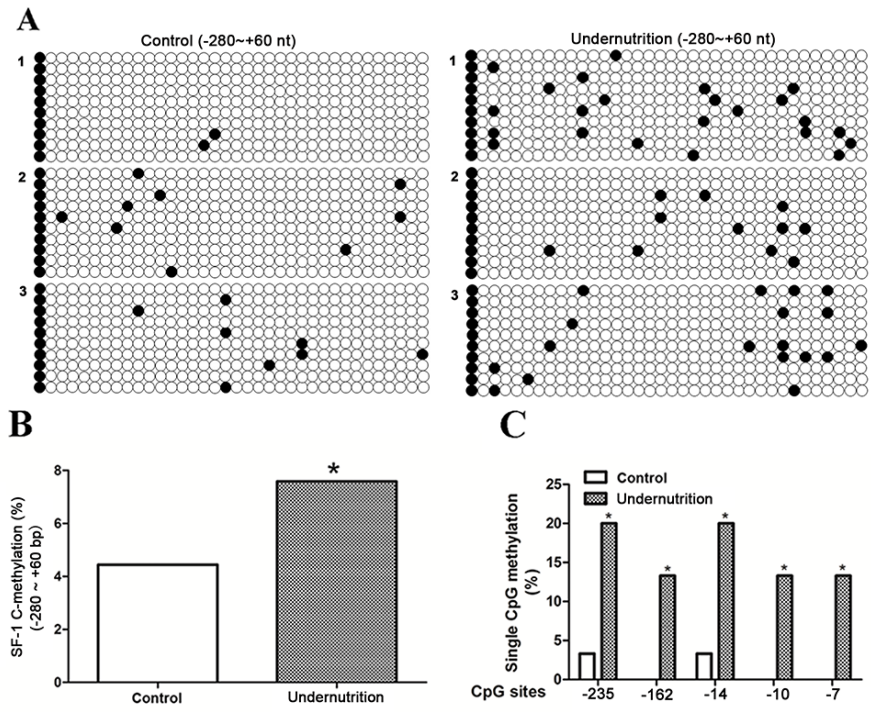

Figure 2: DNA methylation status of steroidogenic factor 1 (SF-1) in maternal rat blood under prenatal maternal undernutrition. CpG methylation status in the $-280 /+60$ domain of rat SF-1 was detected by the bisulfite sequencing PCR (BSP) method. +1 is the transcription start site. (A) The methylation map. Black and white circles represent methylated and unmethylated CpGs, respectively. (B) The total methylation rate of $\mathrm{CpG}$ sites; (C) the $\mathrm{CpG}$ sites with changed methylation frequency. ${ }^{*} P<0.05$, Fisher's exact test, $n=3$ pregnant rats. 


\section{DNA methylation of SF-1 promoter in human maternal blood}

Further, we collected human maternal blood to confirm the DNA methylation status of SF-1 promoter in normal and IUGR pregnancies. The clinical characteristics of pregnant women were presented in Table 3 . There were no intergroup differences in maternal age, gestational age (GA) at delivery and body mass index (BMI). The birth weight was significantly lower in IUGR groups compared with the control group $(P<0.05)$. The methylation status of CpG sites within the $-483 /-28$ domain of SF-1 in maternal blood, which covers the binding sites for transcription factors, was detected by bisulfite sequencing PCR (BSP) analysis. Figure 6A exhibited the methylation map of $\mathrm{CpG}$ rich region in the two groups. The increased total methylation rates of SF-1 promoter were observed in IUGR pregnant women $(P<0.05$, Figure 6B). Few differences at each single $\mathrm{CpG}$ site were shown between the two groups.

\section{DISCUSSION}

\section{DNA methylation patterns in maternal blood may reflect increased placental apoptosis in IUGR}

Prenatal maternal undernutrition is the most common method to establish IUGR models with a high IUGR rate. Based on our previous studies [27], the IUGR rat model was successfully established via a restricted diet from the early to the middle gestation. According to the results of genomic DNA sequencing, maternal blood of the undernutrition group demonstrated changed DNA methylation status of genes related to transcription, apoptosis, cardiac development, neurodevelopment and placental development. These results were in line with our previous studies on nicotine-induced IUGR [28]. Similar results were also found in placentae with earlyonset pre-eclampsia by Blair et al [8]. Cardiovascular system and nervous system are two vital systems for fetal
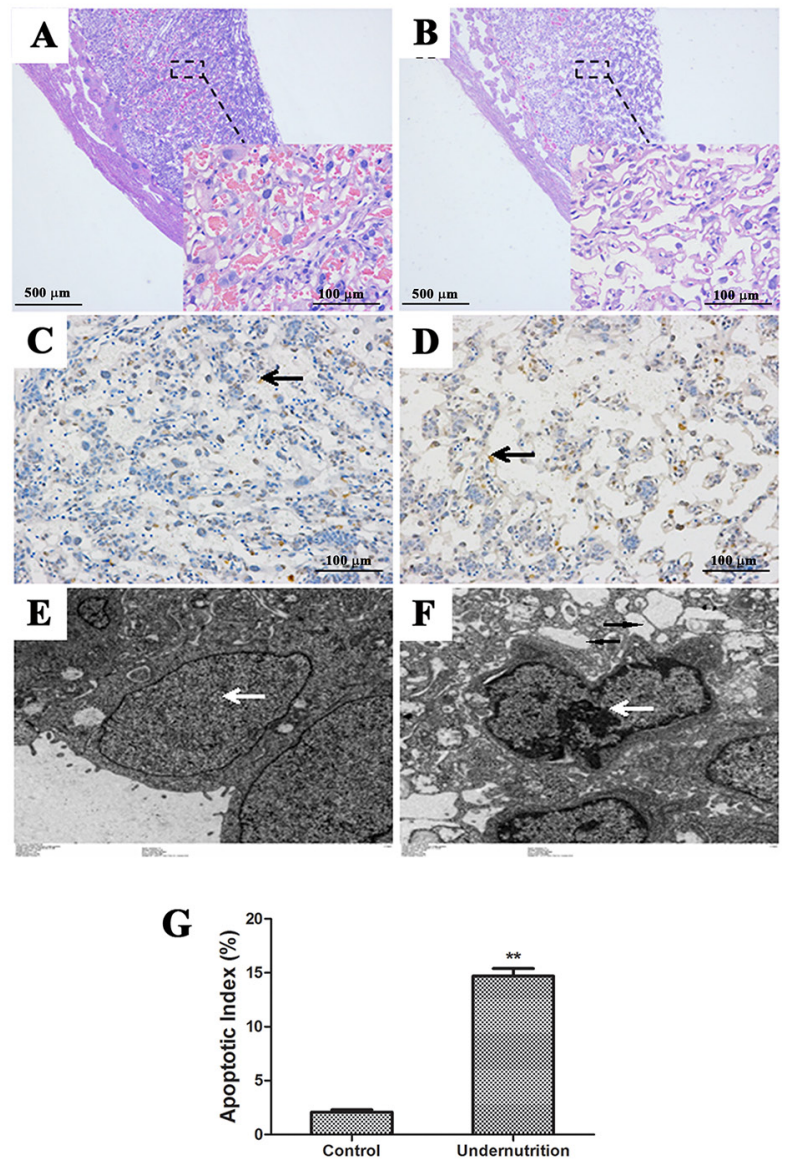

Figure 3: Histological changes and cell apoptosis in rat placentae under prenatal maternal undernutrition. Paraffin sections stained with hematoxylin and eosin (HE) were observed under a light microscope. (A) Control (40×, 200×); (B) undernutrition $(40 \times, 200 \times)$. Syncytiotrophoblast apoptosis in the labyrinth zone was detected by TdT-mediated dUTP nick end labeling (TUNEL). (C) Control (200×); (D) undernutrition $(200 \times)$. Black arrow: syncytiotrophablast. The submicroscopic structure of syncytiotrophoblast was analyzed by transmission electron microscope (TEM). (E) Control $(2000 \times)$; (F) undernutrition (2000×). White arrow: nucleus. Black arrow: vacuoles. (G) Semi-quantitative analysis of TUNEL. Mean $\pm \mathrm{SD},{ }^{*} P<0.05$, two-sided $t$-test, $n=3$ pregnant rats. 
development. It has been reported that symmetric IUGR is associated with the development of cardiovascular disease, coronary heart disease and a relatively larger brain [29, 30]. Damaged placental development and increased apoptosis can inhibit the fetal development through inducing an adverse intrauterine environment $[6,14,31]$. Therefore, we proposed that the above-mentioned DNA methylation changes in maternal blood may reflect the occurrence of IUGR.

Among these changed functional clusters, increased placental apoptosis has been reported to be a possible mechanism for placental dysfunction and the occurrence of IUGR [25, 26]. Meanwhile, excessive placental trophoblast apoptosis has been reported to be reflected by extracellular DNA hypermethylation in maternal plasma [32]. Our previous study has demonstrated that caffeine treatment in rats may induce IUGR by increasing p53dependent placental apoptosis [31]. In our present study, placentae were sampled on GD14, when the placenta is definitively formed [33]. Besides the relatively lower placental weights, the histological damages were observed in HE-staining IUGR placentae. Furthermore, the increased numbers of apoptotic cells was observed in the IUGR placentae using TUNEL and TEM detection. Thus, we speculated that increased placental apoptosis in IUGR may be reflected by the DNA methylation patterns in maternal blood.

\section{Hypermethylated SF-1 in maternal blood could reflect its hypermethylation and increased apoptosis in IUGR placentae}

In this high-throughput sequencing, genes regulating transcription demonstrated the most significantly changed DNA methylation status. And the 4 DMR-associated transcription factors about placenta are crucial for maintaining placental function. Caudal type homeo box 2 (CDX2) enhances trophoblast cell invasion by altering the expression of matrix metalloproteinases [34]. Cryptochrome circadian clock 2 (CRY2) regulates the normal placental phenotype by affecting physiological rhythms [35]. Retinoic acid receptor alpha (RARA)
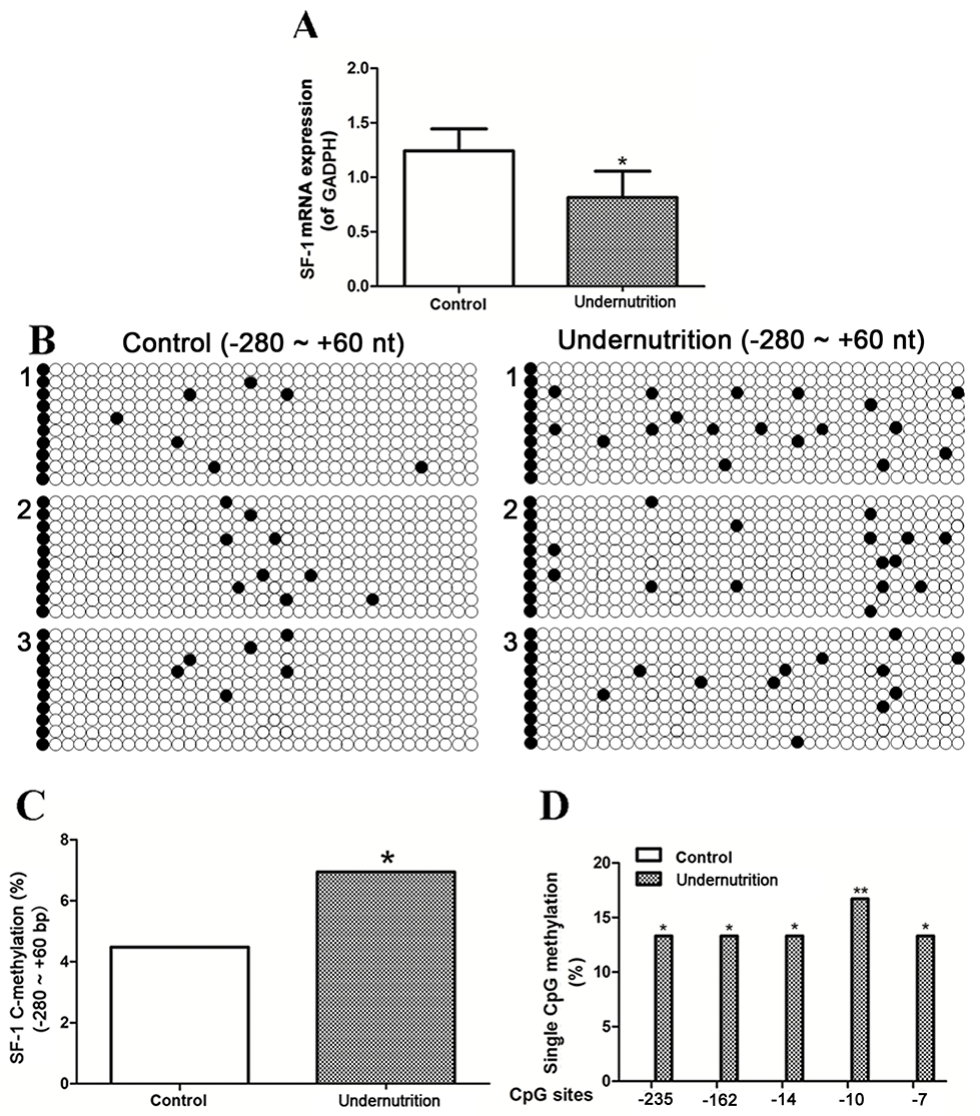

D

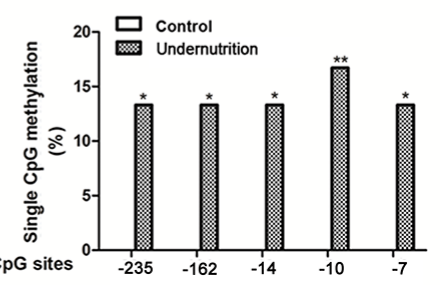

Figure 4: mRNA expression and DNA methylation of steroidogenic factor 1 (SF-1) in rat placenta under prenatal maternal undernutrition. (A) Real-time quantitative PCR was used to detect the mRNA expression. Mean $\pm \mathrm{SD},{ }^{*} P<0.05$, two-sided $t$-test, $n=6$ control vs. 5 undernutrition pregnant rats. CpG methylation status in the $-280 /+60$ domain of rat SF-1 was detected by the bisulfite sequencing PCR (BSP) method. +1 is the transcription start site. (B) The methylation map. Black and white circles represent methylated and unmethylated CpGs, respectively. (C) The total methylation rate of CpG sites; (D) the CpG sites with changed methylation frequency. ${ }^{*} P<0.05,{ }^{* *} P<0.01$, Fisher's exact test, $n=3$ pregnant rats. 
regulates placental steroidogenesis by mediating mRNA expression and enzymatic activity of 17-beta hydroxysteroid dehydrogenase type 2 (HSD17B2) [36]. SF-1 plays an important role in placental morphogenesis. Aberrant DNA methylation and expression of SF-1 can lead to placental apoptosis and IUGR [21, 37]. Meanwhile, SF-1 methylation has been explored in the development of endocrine organs [38]. Inhibited SF-1 expression was observed on GD20 in fetal adrenals of IUGR rats induced by different prenatal exposures [20, 39]. Huang et al. [40] also observed inhibited SF-1 expression in adrenals of adult IUGR rats. In addition, we exposed zebrafish embryos to different IUGR risk factors (caffeine and nicotine) and observed lower fflb expression and lower body length since 48hpf (Supplementary Figure 1). These reports imply that IUGR occurrence may be accompanied by persistently inhibited SF-1 expression. As to maternal blood, notably hypermethylated SF-1 was
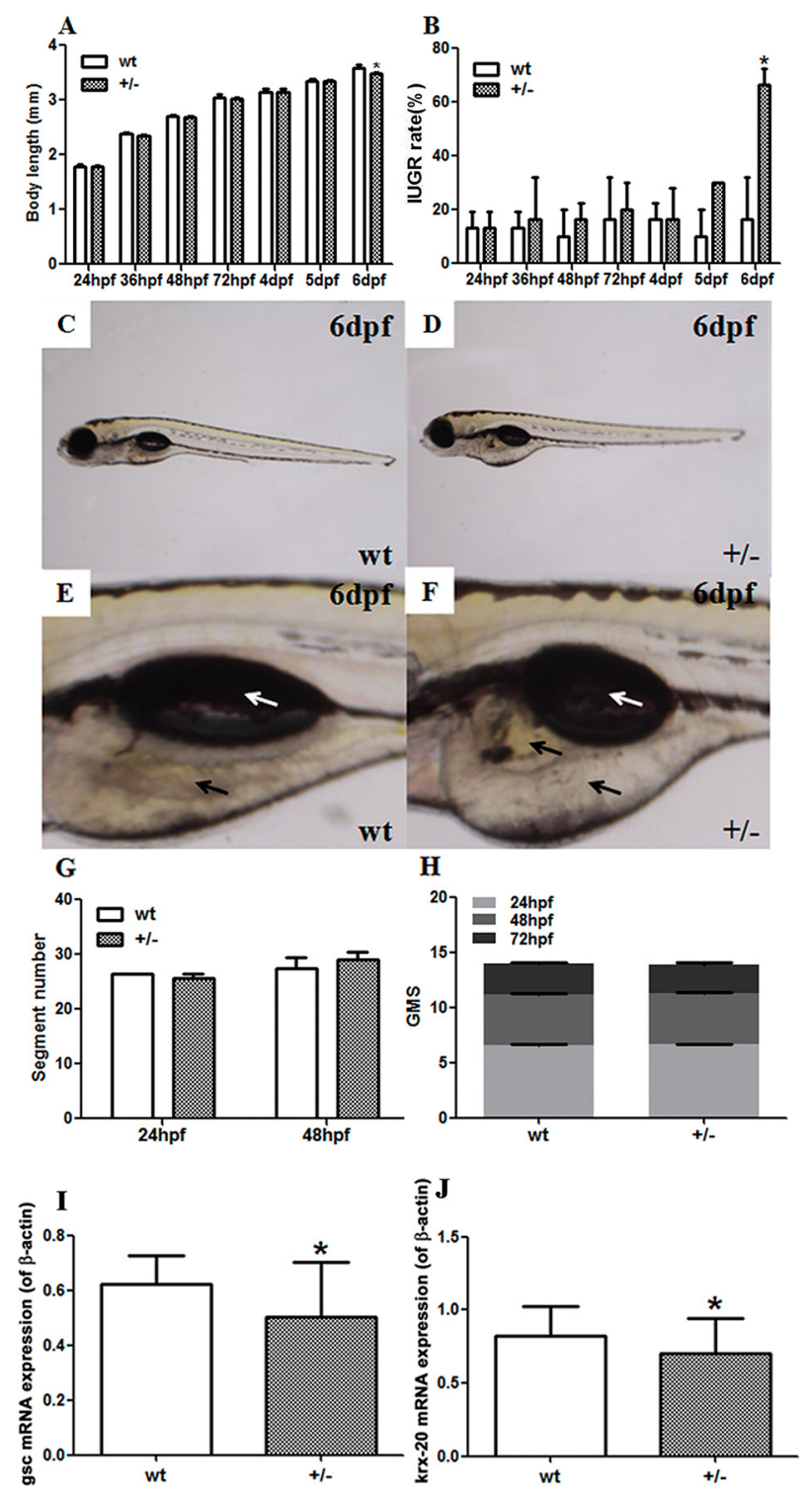

Figure 5: Developmental parameters and mRNA expression of developmental genes in fushi tarazu factor 1b (ff1b) knockout zebrafish by CRISPR/Cas9 technology. (A-D) Developmental parameters of F zebrafish embryos; (A) body lengths; (B) intrauterine growth retardation (IUGR) rates; (C) the whole body of $\mathrm{F}_{3}$ wild-type (WT) embryos at 6 days post-fertilization (dpf); (D) the whole body of $\mathrm{F}_{3}$ mutant-type (MT) embryos at $6 \mathrm{dpf}$; (E) the yolk and swim bladder of $\mathrm{F}_{3}$ WT embryos at 6 dpf; (F) the yolk and swim bladder of $\mathrm{F}_{3} \mathrm{MT}$ embryos at $6 \mathrm{dpf}$. White arrow: swim bladder; black arrow: yolk. (G) Segment number; (H) general morphology score (GMS). Mean $\pm \mathrm{SD},{ }^{*} P<0.05$, two-sided $t$-test, $n=3 \mathrm{~F}_{2}$ zebrafish. Real-time reverse-transcription PCR (RT-PCR) was used to detect the mRNA expression of developmental genes in $\mathrm{F}_{3}$ embryos. (I) goosecoid (gsc) expression in $\mathrm{F}_{3}$ embryos at 12 hours post-fertilization (hpf); (J) krox20 expression in $\mathrm{F}_{3}$ embryos at $12 \mathrm{hpf}$. Mean $\pm \mathrm{SD},{ }^{*} P<0.05$, two-sided $t$-test, $n=3$ embryos. 
Table 3: Clinical characteristics of pregnant women

\begin{tabular}{lcc}
\hline Characteristic & Controls $(\boldsymbol{n}=\mathbf{4})$ & IUGR $(\boldsymbol{n}=\mathbf{4})$ \\
\hline Maternal age $(\mathrm{y})$ & $31.7 \pm 3.2$ & $32.2 \pm 3.5$ \\
BMI $\left(\mathrm{kg} / \mathrm{m}^{2}\right)$ & $19.8 \pm 2.9$ & $22.1 \pm 3.0$ \\
Primigravida (n) & 4 & 4 \\
GA at delivery (wk) & $39.3 \pm 1.1$ & $38.9 \pm 1.8$ \\
Birth weight (kg) & $3.4 \pm 0.4$ & $2.1 \pm 0.3^{*}$ \\
\hline
\end{tabular}

Data were evaluated with two-sided $t$-test, and were given as mean $\pm \mathrm{SD}$ and number. ${ }^{*} P<0.05$ vs control. BMI, body mass index; GA, gestational age; IUGR, intrauterine growth restriction.

observed in our previous prenatal nicotine-induced IUGR rats [28]. Combing our and others' results, we chose SF-1 DNA methylation for further verification as a potential biomarker for IUGR in maternal blood.

The DNA methylation pattern of peripheral blood, which can reflect the global DNA methylation patterns, has been reported to predict the changed DNA methylation pattern occurring in the specific tissue [41]. In this study, BSP analysis confirmed the increased SF-1 methylation in both maternal blood and placentae of the undernutrition group. More importantly, the significantly changed $5 \mathrm{CpG}$ sites in maternal blood were the same as those in the placentae. Thus, DNA methylation status of SF-1 in maternal blood could reflect that in the placenta. Decreased SF-1 mRNA expression was also observed in placentae of IUGR, which was in line with the effects of hypermethylated SF-1 on the corresponding mRNA expression. SF-1 was reported to affect placental apoptosis by regulating the expression of pro-apoptotic genes $[19,21$, 37]. Meanwhile, increased placental apoptosis was reported to be reflected in the maternal blood. For example, apoptotic trophoblast cells may release IUGR-related mRNA into the

$\mathbf{A}$

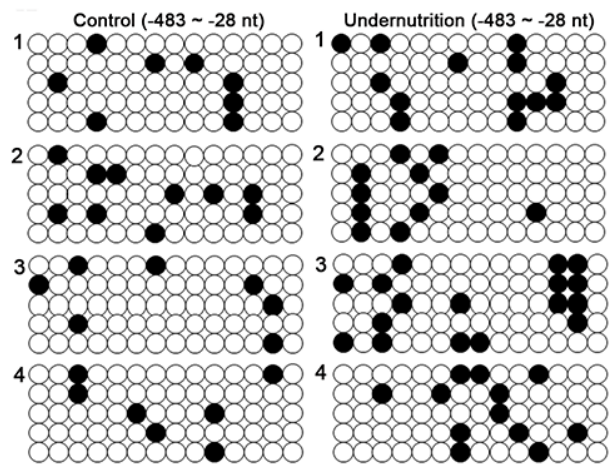

maternal blood, which could be determined to predict IUGR $[5,6]$. By culturing the primary trophoblastic cells, Tjoa et al. [23] observed the relationship between the increased cell-free DNA in the supernatant and the increased cell apoptosis. Thus, we speculated that hypermethylated SF-1, which can inhibit SF-1 expression and increase placental apoptosis, may be reflected in maternal blood and as a potential IUGR biomarker.

\section{Hypermethylated SF-1 in maternal blood could be a potential IUGR biomarker}

Further we aimed to verify the role of DNA methylation of SF-1 in fetal development. At present, the modification of DNA methylation in the specific region of a single gene has not been conducted successfully in vivo. But it is well-known that DNA hypermethylation decreases gene expression at the level of transcription. Therefore, we knocked out maternal SF-1 expression to represent DNA hypermethylation status of SF-1, and investigated the effects of knock-out SF-1 on the embryonic development to verify the relationship between

B

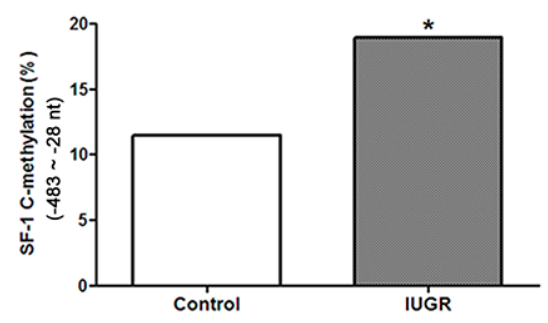

Figure 6: DNA methylation status of steroidogenic factor 1 (SF-1) in human maternal blood of normal pregnancies and pregnancies with intrauterine growth retardation (IUGR). CpG methylation status in the $-483 /-28$ domain of human SF-1 was detected by the bisulfite sequencing PCR (BSP) method. +1 is the transcription start site. (A) The methylation map. Black and white circles represent methylated and unmethylated CpGs, respectively. (B) The total methylation rate of CpG sites. " $P<0.05$, Fisher's exact test, $n=4$ pregnant women. 
increased DNA methylation of SF-1 and IUGR. Due to the shorter experimental period and the higher mutation rate, ff1b (the SF-1 ortholog in zebrafish) was knocked out in zebrafish by CRISPR/Cas9 technology. The mutant zebrafish were bred for three generations to minimize the off-target effects of the genome editing.

In this study, we successfully developed hereditable fflb knockout MT zebrafish, which can be reflected by the decreased fflb mRNA expression in $\mathrm{F}_{2}$ MT zebrafish (Supplementary Figure 2). The mutant homozygotes in our study can only survive up to $15 \mathrm{dpf}$, which is in line with the report by Chai et al [42]. Thus, mutant heterozygotes were used for the subsequent experiments. The results showed that the $\mathrm{F}_{3}$ MT embryos had inhibited developmental parameters and increased IUGR rates at $6 \mathrm{dpf}$, which is equivalent to GD18.5 in mice [43]. At the genetic level, we also observed the significantly reduced expression of two ozganogenetic biomarkers (gsc and krx-20) in 12-hpf
MT embryos [44, 45]. Thus, the knockout of maternal SF-1 could inhibit the expression of developmental genes since the early prenatal phase when the phenotypes are still inconspicuous. The delayed phenotypic changes may be resulted from the use of heterozygotes. These results demonstrated that decreased SF-1 expression can cause developmental inhibition and IUGR.

Furthermore, we compared the DNA methylation status of SF-1 promoter in human maternal blood between normal pregnancy and pregnancy with IUGR. In order to reduce sampling deviation, age, $\mathrm{BMI}$ and gestational age were kept consistent between the two groups. Although no single $\mathrm{CpG}$ sites of the SF-1 promoter showed significantly different DNA methylation rates between the two groups, the total methylation frequency of SF-1 promoter in the IUGR group was much higher than that of the control. These results implied the possibility of SF-1 hypermethylation in maternal blood as a potential IUGR

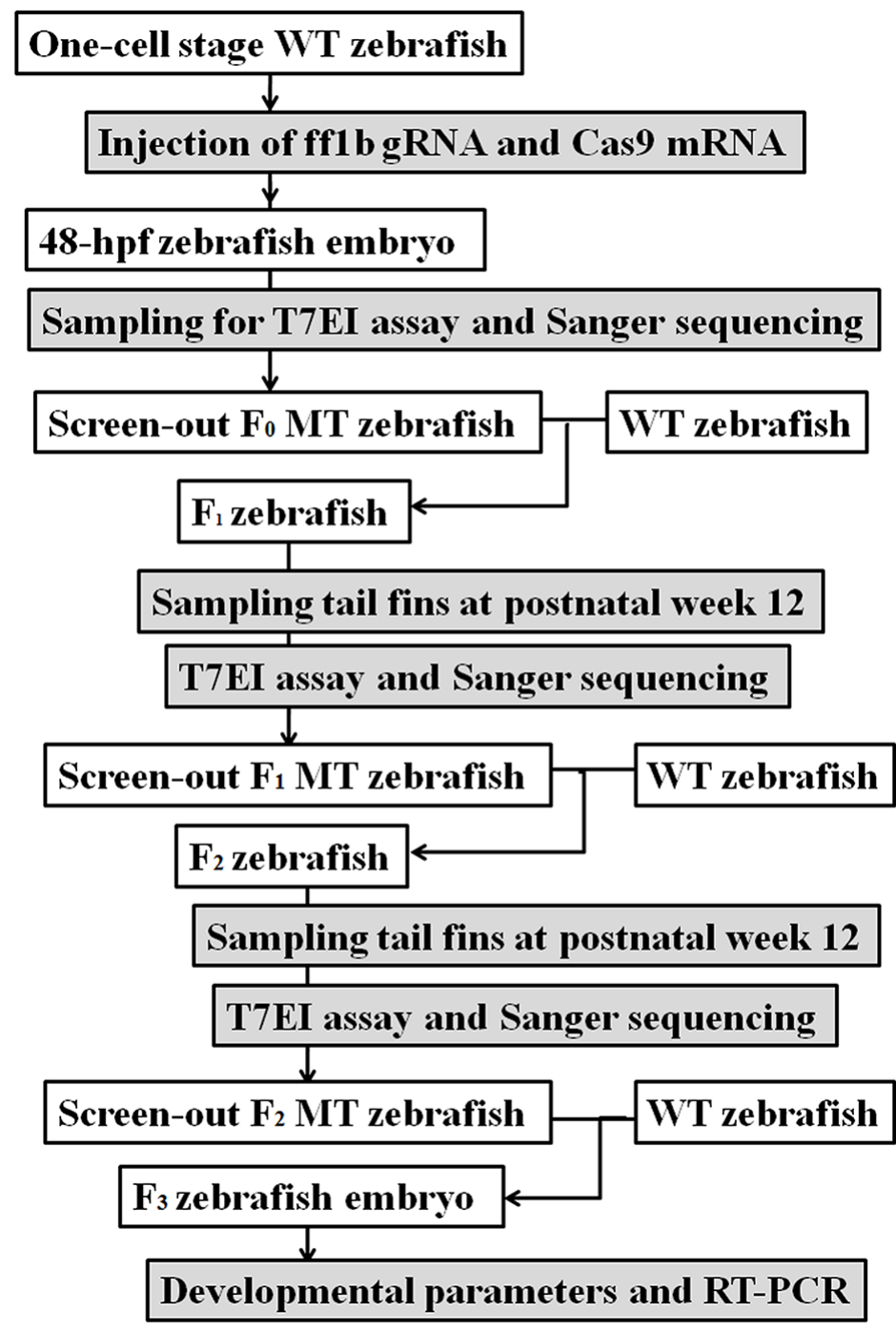

Figure 7: The experimental scheme for CRISPR/Cas9 targeted fushi tarazu factor 1b (ff1b) mutation in zebrafish. hpf: hour post-fertilization; MT: mutant-type; RT-PCR: reverse-transcription PCR; T7EI: T7 endonuclease I; WT: wild-type. 
biomarker in clinic, despite the relatively low number of pregnant women in this study.

\section{MATERIALS AND METHODS}

\section{Chemicals and reagents}

Isoflurane was obtained from Baxter Healthcare Co. (Deerfield, IL, USA). The TUNEL kit was from Promega Co. (Madison, WI, USA). The genomic DNA preparation kit was purchased from Vitagene Co. (Hangzhou, China). The pGEM-T Easy vector was from Promega Co. (Madison, WI, USA). T7 endonuclease I (T7EI), pXT 7 vector and $\mathrm{pMD}$ 19-T vector were purchased from New England Biolabs Inc. (Beverly, MA, USA). The mMESSAGE mMACHINE kit was from Ambion (Austin, TX, USA). The TIANgel Midi purification kit was obtained from Tiangen Biotech Co., Ltd. (Beijing, China). The EZ DNA methylation kit was provided by Zymo Research Co. (Orange, CA, USA). All other chemicals and reagents were of analytical grade.

\section{Experiments in rats}

\section{Animals and treatments}

Specific pathogen-free Wistar rats, females weighing $200 \pm 20 \mathrm{~g}$ and males weighing $280 \pm 20 \mathrm{~g}$ were from the Experimental Center of the Hubei Medical Scientific Academy (No. 2008-0005, Hubei, China). The rat experiments were performed in the Center for Animal Experimentation of Wuhan University (Wuhan, Hubei, China), which has been accredited by the Association for Assessment and Accreditation of Laboratory Animal Care (AAALAC) International.

Two female rats were mated with one male rat overnight after 7 days of acclimation. The day to observe vaginal smear with sperm cells was designated as GD0. Rats in the control group were allowed free access to standard chow and water, while rats in the undernutrition group were put on a restricted diet $(50 \%$ food intake of the GD-matched control rats) from GD0. On GD14, pregnant rats were anesthetized with isoflurane and euthanized by decapitation. Maternal blood was collected in sodium citrate tubes. Fetuses and placentae were weighed after being dried on filter paper. IUGR was diagnosed when a fetal weight was two standard deviations lower than the mean body weight of control group [46]. IUGR rates were calculated by dividing the number of IUGR in each litter by the total pups of the litter. Three placentae in each group were randomly selected for fixing in $10 \%$ neutral formalin solution to make paraffin slices. Another three placentae in each group were randomly selected and immersed in 3\% glutaraldehyde $1.5 \%$ paraformaldehyde solution for TEM analysis. The remaining placentae were stored at $-80^{\circ} \mathrm{C}$.

\section{Histopathological measurement of placentae}

For light microscopy analysis, $5 \mu \mathrm{m}$-thick paraffin sections were stained with HE and TUNEL, respectively. For TEM analysis, samples were postfixed for $1.5 \mathrm{~h}$ in $1 \%$ osmium tetroxide $1.5 \%$ potassium ferrocyanide solution, dehydrated in graded concentrations of ethanol, and embedded in Epon 618. Ultrathin sections approximately $70 \mathrm{~nm}$ thick were stained with uranyl acetate and lead citrate, and examined using a Hitachi H600 TEM (Hitachi, Co., Tokyo, Japan).

\section{High-throughput bisulfite sequencing in maternal blood}

Genomic DNA was isolated from 3 samples of maternal blood using the genomic DNA preparation kit. $5 \mathrm{ng}$ of genomic DNA was fragmented into 400-600 nt using M220 Focused-ultrasonicator from Covaris Inc. (Woburn, MA, USA), followed by bisulfite conversion with the EZ DNA methylation kit. Bisulfite-converted DNA was used for illumina pair-end library preparation with the EpiGonme Methyl-seq kit. The libraries were applied to illumine Nextseq 500 system for 150 nt pairend high-throughput sequencing by ABlife Inc. (Wuhan, Hubei, China). DMRs were identified based on the DNA methylation status of every sample. Among the top 3000 DMR associated genes, functional clustering analysis was employed to screen out the functional clusters and genes needing subsequent confirmation.

\section{BSP analysis in maternal blood and placentae}

The methylation status of $\mathrm{CpG}$ sites in the $-280 /+60$ domain of SF-1 proximal promoter was determined by BSP analysis. The DNA sequence of this domain was referred to UCSC Genome Browser (http://genome.ucsc. edu/) and demonstrated in Supplementary Database 1. 10 clones were sequenced for each sample. The detailed protocols were published in our previous study [20].

\section{Real-time RT-PCR analysis in placentae}

Placental SF-1 mRNA expression was determined by real-time RT-PCR. Detailed protocols were published in our previous study [20].

\section{Experiments in zebrafish}

\section{Maintenance of zebrafish}

WT AB strain zebrafish were supplied by the Key Laboratory of Biodiversity and Conservation of Aquatic Organism, Institute of Hydrobiology, Chinese Academy of Sciences (Wuhan, Hubei, China). Zebrafish were raised at $28 \pm 0.5^{\circ} \mathrm{C}$ in a $14: 10 \mathrm{~h}$ light: dark cycle in a closed flowthrough system. Zebrafish embryos were obtained from spawning adults in groups of 20 males and 10 females in tanks overnight. Spawning was induced in the morning when the light was turned on. Normally developed embryos were selected at 4-5 hpf. 


\section{CRISPR/Cas9 targeted mutation technology}

fflb, the SF-1 ortholog, was knocked out in zebrafish through CRISPR/Cas9 targeted mutation [47]. The experimental scheme was shown in Figure 7. The fulllength Cas 9 cDNA was cloned into the pXT 7 vector. The capped Cas 9 mRNA was produced using the mMESSAGE mMACHINE kit. The corresponding fflb gRNA sequence was cloned into the pMD 19-T vector, the primers of which (forward: 5'-GCGATGCTACATTCAGTGTC-3'; reverse: 5'-CCGTCAAATAAGATAACAGGG-3') were designed at http://zifit.partners.org/ZiFiT/. The gRNA sequence was amplified into double-stranded DNA by PCR. And the corresponding primers were as follows: forward: 5'-TGTAATACGACTCACTATAGAGGAGCT TTGCCCGGTGTGGTTTTAGAGCTAGA-3'; reverse: 5'-AGCACCGACTCGGTGCCACT-3'. The products were identified by agarose gel electrophoresis and purified by the TIANgel Midi purification kit.

One-cell stage zebrafish embryos were injected with $8 \mathrm{~nL}$ solution containing $20 \mathrm{ng} / \mu \mathrm{L}$ gRNA and 300 $\mathrm{ng} / \mu \mathrm{L}$ Cas 9 mRNA. Genomic DNA was isolated from these injected embryos at $48 \mathrm{hpf}$ and was digested in 5 $\mu \mathrm{g} / \mathrm{mL}$ proteinase $\mathrm{K}$ for $90 \mathrm{~min}$ at $65^{\circ} \mathrm{C}$, followed by 15 min at $95^{\circ} \mathrm{C}$. The genomic targeted region was amplified by PCR. Primers (annealing $58^{\circ} \mathrm{C}, 30 \mathrm{~s}$ ) were as follows: forward: 5'-GAGCTTTCAGAGAACATTTAGAA-3'; reverse: 5'-CAGCACACCACAGTTTACTGTAG-3'. The PCR amplicon was then denatured slowly and reannealed to facilitate the heteroduplex formation. The product was digested with 5 units of T7EI at $37^{\circ} \mathrm{C}$ for $90 \mathrm{~min}$. Then the digested samples were analyzed by agarose gel electrophoresis. For further confirmation, the purified PCR products were cloned into the pGEM-T easy vector and analyzed by Sanger sequencing.

The screen-out MT zebrafish, which were taken as the $\mathrm{F}_{0}$ zebrafish, were backcrossed with the WT zebrafish at postnatal week 12. At $12 \mathrm{hpf}$, dead or deformed $\mathrm{F}_{1}$ embryos were removed. The tail fins of $F_{1}$ zebrafish were collected at postnatal week 12 and analyzed as described above to search for MT zebrafish. F, MT zebrafish were backcrossed with the WT zebrafish at postnatal week 12. $\mathrm{F}_{2}$ MT zebrafish were screened out according to the screening methods in $\mathrm{F}_{1}$ zebrafish.

\section{Development of $F_{3}$ embryos}

At postnatal week 12, $\mathrm{F}_{2}$ MT zebrafish were backcrossed with the WT zebrafish. At $12 \mathrm{hpf}$, dead or deformed $\mathrm{F}_{3}$ embryos were removed. The body length, yolk sac absorption and IUGR rate were recorded at $24 \mathrm{hpf}, 36 \mathrm{hpf}, 48 \mathrm{hpf}, 72 \mathrm{hpf}$, 4dpf, $5 \mathrm{dpf}$ and $6 \mathrm{dpf}$, respectively. The embryo was taken as IUGR when its body length was $10 \%$ shorter than the mean body length of the control group [46]. The body segment number was recorded at $24 \mathrm{hpf}$ and $48 \mathrm{hpf}$. And embryonic development was scored at $24 \mathrm{hpf}, 48 \mathrm{hpf}$ and $72 \mathrm{hpf}$, following the GMS [48].

\section{Real-time RT-PCR analysis}

Real-time RT-PCR was used to detect fflb mRNA expression in $\mathrm{F}_{2}$ zebrafish at postnatal week 12, and the mRNA expression of gsc and krx-20 in 12-hpf $\mathrm{F}_{3}$ embryos. Total RNA was isolated from the tail fins of $\mathrm{F}_{2}$ zebrafish and $\mathrm{F}_{3}$ embryos as described in RT-PCR analysis in placentae. Each sample was normalized on the basis of $\beta$-actin mRNA content. Primers and annealing conditions were shown in Supplementary Table 1.

\section{SF-1 methylation analysis in peripheral blood of pregnant women with IUGR}

\section{Participants}

In this study, all subjects were recruited between February 2014 and May 2015 from routine prenatal screening in the Department of Obstetrics and Gynecology at Enshi General Hospital, Hubei, China. Eight Han Chinese primiparae were selected (at 28-32 gestational weeks) for normal or IUGR singleton pregnancies. IUGR was diagnosed when fetal abdominal circumference and/or estimated fetal weight were below the tenth percentile for GA, with a reduction of growth on repeated ultrasonographic evaluation and abnormal umbilical artery blood flow waveform on Doppler examination. None of the participants had histories of preexisting hypertension, diabetes mellitus, liver disease, or chronic kidney disease.

\section{Peripheral blood sampling and DNA isolation}

Maternal peripheral blood samples were taken by venipuncture. $3 \mathrm{~mL}$ of maternal blood was collected into an EDTA tube. Genomic DNA in maternal blood was extracted by the genomic DNA preparation kit and stored at $-20^{\circ} \mathrm{C}$ for BSP analysis.

\section{BSP analysis}

The methylation status of CpG sites in the -483/28 domain of SF-1 proximal promoter was determined by BSP analysis. The DNA sequence of this domain was referred to UCSC Genome Browser (http://genome.ucsc. edu/) and demonstrated in Supplementary Database 1. 5 clones were sequenced for each sample. Two primers were used for PCR amplification (SF1-1 and SF1-2), which cover the $\mathrm{CpG}$ rich region of proximal SF-1 promoter. Primers of SF1-1 (-483 nt -190 nt) were as follows: forward: 5'-AAAAGAGGTGGAAGTAGTAGGT-3'; reverse: 5'-CCTTAACCAACTAA CTATTCCA-3'. Primers of SF1-2 (-321 nt -28 nt) were as follows: forward: 5'-GGGTGGGGGAGTAGTTTATAAA-3'; reverse: 5'-CCAATTAATCTCTACCCCCAC-3'. The amplification conditions were as follows: initial denaturation at $98^{\circ} \mathrm{C}$ for $2 \mathrm{~min}$; 45 cycles of denaturation at $95^{\circ} \mathrm{C}$ for $30 \mathrm{~s}$, anneal at $60^{\circ} \mathrm{C}$ for $30 \mathrm{~s}$, and extension at $72^{\circ} \mathrm{C}$ for $30 \mathrm{~s}$; a final elongation step at $72^{\circ} \mathrm{C}$ for $10 \mathrm{~min}$. 


\section{Ethics statement}

All procedures performed in studies involving animals were in accordance with the Guidelines for Animal Research, and were approved by the Ethical and Research Committee of Medical College of Wuhan University (No. 00092764). All procedures performed in studies involving human participants were in accordance with the ethical standards of the institutional and/or national research committee and with the 1964 Helsinki declaration and its later amendments or comparable ethical standards. The human subject research was approved by the Ethical and Research Committee of Wuhan University (No. 12016), China. The written informed consents were obtained from all participants included in the study.

\section{Statistical analysis}

SPSS 15.0 from SPSS Science Inc. (Chicago, IL, USA) and Graphpad Prism 5.0 from GraphPad Software (La Jolla, CA, USA) were used for data analysis. All measurement data were expressed as the mean $\pm \mathrm{SD}$ and evaluated with two-sided $t$-test. Enumeration data, such as IUGR rates were firstly calculated and then arcsine square-root transformed to make the data following normal distribution [49]. The methylation frequencies were evaluated by Fisher's exact test. Statistical significance was set at $P<0.05$.

\section{CONCLUSIONS}

In summary, distinct DNA methylation profile exists in maternal blood of IUGR rats. SF-1 plays an important role in fetal development and the occurrence of IUGR. Hypermethylated SF-1 in the maternal rat blood could be a potential IUGR biomarker. The underlying mechanism may be as follows: hypermethylated SF-1 inhibited its gene expression in the placenta, which could lead to increased placental apoptosis and IUGR. As apoptotic cells flows into maternal blood, the changed DNA methylation patterns in apoptotic placentae can be reflected in maternal blood. To our knowledge, we firstly used genomic DNA methylation sequencing to screen out potential IUGR biomarkers in maternal blood from the perspective of DNA methylation. It will provide evidence for IUGR pathophysiology and non-invasive prenatal prediction of IUGR. Further analysis for SF-1 hypermethylation in more types of tissues on a larger scale will be needed to confirm the role of hypermethylated SF-1 in prenatal IUGR diagnosis.

\section{Abbreviations}

BMI: body mass index; BSP: bisulfite sequencing PCR; CDX2: caudal type homeo box 2; CRISPR/Cas9: clustered regularly interspaced short palindromic repeats/ CRISPR-associated protein 9; CRY2: cryptochrome circadian clock 2; DMR: differentially methylated region; dpf: day post-fertilization; ff $1 \mathrm{~b}$ : fushi tarazu factor $1 \mathrm{~b}$; GA: gestational age; GD: gestational day; GMS: general morphology score; gsc: goosecoid; HE: hematoxylin and eosin; hpf: hour post-fertilization; HSD17B2: 17-beta hydroxysteroid dehydrogenase type 2; IUGR: intrauterine growth retardation; MT: mutanttype; RARA: retinoic acid receptor alpha; RT-PCR: reverse-transcription PCR; SF-1: steroidogenic factor-1; T7EI: T7 endonuclease I; TEM: transmission electron microscope; TUNEL: TdT-mediated dUTP nick end labelling; WT: wild-type.

\section{Author contributions}

LPM and JP designed experiments. DMW, LPM, GLS, YL, HXL, YL, and JP performed experiments. DMW and LPM analyzed data. DMW and JP wrote the paper. All authors read and approved the final manuscript.

\section{CONFLICTS OF INTEREST}

No potential conflicts of interest were disclosed.

\section{FUNDING}

This work was supported by Grants from the National Natural Science Foundation of China (No. 81673215, 81273107), and the Applied Fundamental Research Project of Wuhan (No. 2017060201010199).

\section{REFERENCES}

1. Cunningham FG, Leveno KJ, Bloom SL, Hauth JC, Rouse DJ, Spong CY. Williams Obstetrics. 23rd ed. New York: The McGraw-Hill Press; 2010.

2. Genbacev O, McMaster MT, Zdravkovic T, Fisher SJ. Disruption of oxygen-regulated responses underlies pathological changes in the placentas of women who smoke or who are passively exposed to smoke during pregnancy. Reprod Toxicol. 2003; 17:509-518.

3. Gluckman PD, Harding JE. The physiology and pathophysiology of intrauterine growth retardation. Horm Res. 1997; 48:11-16.

4. Silveira VM, Horta BL. [Birth weight and metabolic syndrome in adults: meta-analysis]. [Article in Portuguese]. Rev Saude Publica. 2008; 42:10-18.

5. Whitehead CL, Walker SP, Mendis S, Lappas M, Tong S. Quantifying mRNA coding growth genes in the maternal circulation to detect fetal growth restriction. Am J Obstet Gynecol. 2013; 209:133.e1-133.e9.

6. Whitehead CL, Walker SP, Ye L, Mendis S, Kaitu'uLino TJ, Lappas M, Tong S. Placental specific mRNA in the maternal circulation are globally dysregulated in pregnancies complicated by fetal growth restriction. J Clin Endocrinol Metab. 2013; 98:E429-E436. 
7. Bamfo JE, Odibo AO. Diagnosis and management of fetal growth restriction. J Pregnancy. 2011; 2011:640715.

8. Blair JD, Yuen RK, Lim BK, McFadden DE, von Dadelszen P, Robinson WP. Widespread DNA hypomethylation at gene enhancer regions in placentas associated with early-onset pre-eclampsia. Mol Hum Reprod. 2013; 19:697-708.

9. MacLennan NK, James SJ, Melnyk S, Piroozi A, Jernigan S, Hsu JL, Janke SM, Pham TD, Lane RH. Uteroplacental insufficiency alters DNA methylation, one-carbon metabolism, and histone acetylation in IUGR rats. Physiol Genomics. 2004; 18:43-50.

10. Ivorra C, Fraga MF, Bayón GF, Fernández AF, GarciaVicent C, Chaves FJ, Redon J, Lurbe E. DNA methylation patterns in newborns exposed to tobacco in utero. J Transl Med. 2015; 13:25.

11. Chowdhury S, Erickson SW, MacLeod SL, Cleves MA, Hu P, Karim MA, Hobbs CA. Maternal genome-wide DNA methylation patterns and congenital heart defects. PLoS One. 2011; 6:e16506.

12. Papageorgiou EA, Karagrigoriou A, Tsaliki E, Velissariou V, Carter NP, Patsalis PC. Fetal-specific DNA methylation ratio permits noninvasive prenatal diagnosis of trisomy 21 . Nat Med. 2011; 17:510-513.

13. Kim MJ, Kim SY, Park SY, Ahn HK, Chung JH, Ryu HM. Association of fetal-derived hypermethylated RASSF1A concentration in placenta-mediated pregnancy complications. Placenta. 2013; 34:57-61.

14. Leeuwerke M, Eilander MS, Pruis MG, Lendvai Á, Erwich JJ, Scherjon SA, Plösch T, Eijsink JJ. DNA methylation and expression patterns of selected genes in first-trimester placental tissue from pregnancies with small-for-gestational-age infants at birth. Biol Reprod. 2016; 94:37.

15. Sifakis S, Koukou Z, Spandidos DA. Cell-free fetal DNA and pregnancy-related complications (review). Mol Med Rep. 2015; 11:2367-2372.

16. Gascoin-Lachambre G, Buffat C, Rebourcet R, Chelbi ST, Rigourd V, Mondon F, Mignot TM, Legras E, Simeoni $\mathrm{U}$, Vaiman D, Barbaux S. Cullins in human intra-uterine growth restriction: expressional and epigenetic alterations. Placenta. 2010; 31:151-157.

17. Reamon-Buettner SM, Buschmann J, Lewin G. Identifying placental epigenetic alterations in an intrauterine growth restriction (IUGR) rat model induced by gestational protein deficiency. Reprod Toxicol. 2014; 45:117-124.

18. Bamberger AM, Ezzat S, Cao B, Wong M, Parker KL, Schulte HM, Asa SL. Expression of steroidogenic factor-1 (SF-1) mRNA and protein in the human placenta. Mol Hum Reprod. 1996; 2:457-461.

19. Parviainen H, Schrade A, Kiiveri S, Prunskaite-Hyyryläinen R, Haglund C, Vainio S, Wilson DB, Arola J, Heikinheimo $\mathrm{M}$. Expression of Wnt and TGF- $\beta$ pathway components and key adrenal transcription factors in adrenocortical tumors: association to carcinoma aggressiveness. Pathol Res Pract. 2013: 209:503-509.

20. Ping J, Wang JF, Liu L, Yan YE, Liu F, Lei YY, Wang H. Prenatal caffeine ingestion induces aberrant DNA methylation and histone acetylation of steroidogenic factor 1 and inhibits fetal adrenal steroidogenesis. Toxicology. 2014; 321:53-61.

21. Rena V, Flores-Martín J, Angeletti S, Panzetta-Dutari GM, Genti-Raimondi S. StarD7 gene expression in trophoblast cells: contribution of SF-1 and Wnt-beta-catenin signaling. Mol Endocrinol. 2011; 25:1364-1375.

22. Swarup V, Rajeswari MR. Circulating (cell-free) nucleic acids--a promising, non-invasive tool for early detection of several human diseases. Febs Lett. 2007; 581:795-799.

23. Tjoa ML, Cindrova-Davies T, Spasic-Boskovic O, Bianchi DW, Burton GJ. Trophoblastic oxidative stress and the release of cell-free feto-placental DNA. Am J Pathol. 2006; 169:400-404.

24. Shang X, Su J, Wan Q, Su J, Feng X. CpG methylation in the 5'-flanking region of LGP2 gene lacks association with resistance/susceptibility to GCRV but contributes to the differential expression between muscle and spleen tissues in grass carp, Ctenopharyngodon idella. Fish Shellfish Immunol. 2014; 40:154-163.

25. El-Baz MA, El-Deeb TS, El-Noweihi AM, Mohany KM, Shaaban OM, Abbas AM. Environmental factors and apoptotic indices in patients with intrauterine growth retardation: a nested case-control study. Environ Toxicol Pharmacol. 2015; 39:589-596.

26. Longtine MS, Chen B, Odibo AO, Zhong Y, Nelson DM. Villous trophoblast apoptosis is elevated and restricted to cytotrophoblasts in pregnancies complicated by preeclampsia, IUGR, or preeclampsia with IUGR. Placenta. 2012; 33:352-359.

27. Zhang L, Xu D, Zhang B, Liu Y, Chu F, Guo Y, Gong J, Zheng X, Chen L, Wang H. Prenatal food restriction induces a hypothalamic-pituitary-adrenocortical axis-associated neuroendocrine metabolic programmed alteration in adult offspring rats. Arch Med Res. 2013; 44:335-345.

28. Liu L, Ping J, Wang H. DNA methylation profiles of maternal peripheral blood and intrauterine growth restriction. Drug Metab Rev. 2014; 45:49-50.

29. Poudel R, McMillen IC, Dunn SL, Zhang S, Morrison JL. Impact of chronic hypoxemia on blood flow to the brain, heart, and adrenal gland in the late-gestation IUGR sheep fetus. Am J Physiol Regul Integr Comp Physiol. 2015; 308:R151-R162.

30. van der Linde S, Romano T, Wadley G, Jeffries AJ, Wlodek $\mathrm{ME}$, Hryciw DH. Growth restriction in the rat alters expression of cardiac JAK/STAT genes in a sex-specific manner. J Dev Orig Health Dis. 2014; 5:314-321.

31. Huang J, Zhou S, Ping J, Pan X, Liang G, Xu D, Kou H, Bao C, Wang H. Role of p53-dependent placental apoptosis 
in the reproductive and developmental toxicities of caffeine in rodents. Clin Exp Pharmacol Physiol. 2012; 39:357-363.

32. Rahat B, Thakur S, Bagga R, Kaur J. Epigenetic regulation of STAT5A and its role as fetal DNA epigenetic marker during placental development and dysfunction. Placenta. 2016; 44:46-53.

33. Fonseca BM, Correia-da-Silva G, Teixeira NA. The rat as an animal model for fetoplacental development: a reappraisal of the post-implantation period. Reprod Biol. 2012; 12:97-118.

34. Jia RZ, Ding GC, Gu CM, Huang T, Rui C, Wang YX, Lu Q. CDX2 enhances HTR-8/SVneo trophoblast cell invasion by altering the expression of matrix metalloproteinases. Cell Physiol Biochem. 2014; 34:628-636.

35. Waddell BJ, Wharfe MD, Crew RC, Mark PJ. A rhythmic placenta? Circadian variation, clock genes and placental function. Placenta. 2012; 33:533-539.

36. Su EJ, Cheng YH, Chatterton RT, Lin ZH, Yin P, Reierstad $\mathrm{S}$, Innes J, Bulun SE. Regulation of 17-beta hydroxysteroid dehydrogenase type 2 in human placental endothelial cells. Biol Reprod. 2007; 77:517-525.

37. Flores-Martín J, Rena V, Márquez S, Panzetta-Dutari GM, Genti-Raimondi S. StarD7 knockdown modulates ABCG2 expression, cell migration, proliferation, and differentiation of human choriocarcinoma JEG-3 cells. PLoS One. 2012; 7:e44152.

38. Hoivik EA, Bjanesoy TE, Bakke M. Epigenetic regulation of the gene encoding steroidogenic factor-1. Mol Cell Endocrinol. 2013; 371:133-139.

39. Yan YE, Liu L, Wang JF, Liu F, Li XH, Qin HQ, Wang H. Prenatal nicotinic exposure suppresses fetal adrenal steroidogenesis via steroidogenic factor 1 (SF-1) deacetylation. Toxicol Appl Pharmacol. 2014; 277:231-241.

40. Huang H, He Z, Zhu C, Liu L, Kou H, Shen L, Wang H. Prenatal ethanol exposure-induced adrenal developmental abnormality of male offspring rats and its possible intrauterine programming mechanisms. Toxicol Appl Pharmacol. 2015; 288:84-94.
41. Kundakovic M, Gudsnuk K, Herbstman JB, Tang D, Perera FP, Champagne FA. DNA methylation of BDNF as a biomarker of early-life adversity. Proc Natl Acad Sci U S A. 2015; 112:6807-6813.

42. Chai C, Liu YW, Chan WK. Fflb is required for the development of steroidogenic component of the zebrafish interrenal organ. Dev Biol. 2003; 260:226-244.

43. Irie N, Kuratani S. Comparative transcriptome analysis reveals vertebrate phylotypic period during organogenesis. Nat Commun. 2011; 2:248.

44. Oxtoby E, Jowett T. Cloning of the zebrafish krox-20 gene (krx-20) and its expression during hindbrain development. Nucleic Acids Res. 1993; 21:1087-1095.

45. Stachel SE, Grunwald DJ, Myers PZ. Lithium perturbation and goosecoid expression identify a dorsal specification pathway in the pregastrula zebrafish. Development. 1993; 117:1261-1274.

46. Engelbregt MJ, van Weissenbruch MM, Popp-Snijders C, Lips P, Delemarre-van de Waal HA. Body mass index, body composition, and leptin at onset of puberty in male and female rats after intrauterine growth retardation and after early postnatal food restriction. Pediatr Res. 2001; 50:474-478.

47. Mazilu JK, Powers JW, Lin S, McCabe ER. ff1b, the SF1 ortholog, is important for pancreatic islet cell development in zebrafish. Mol Genet Metab. 2010; 101:391-394.

48. Hermsen SA, van den Brandhof EJ, van der Ven LT, Piersma AH. Relative embryotoxicity of two classes of chemicals in a modified zebrafish embryotoxicity test and comparison with their in vivo potencies. Toxicol In Vitro. 2011; 25:745-753.

49. Vidmar T, Freshwater L, Collins R. Understanding statistics in developmental and reproductive toxicology. In: Hood RD, Editor. Developmental and reproductive toxicology: a practical approach. Florence, KY: CRC Press; 2011. pp. 542-562. 